\title{
Toxicity studies of six types of carbon nanoparticles in a chicken-embryo model
}

\author{
This article was published in the following Dove Press journal: \\ International Journal of Nanomedicine \\ 7 April 2017 \\ Number of times this article has been viewed
}

\section{Natalia Kurantowicz' \\ Ewa Sawosz' \\ Gabriela Halik' \\ Barbara Strojny' \\ Anna Hotowy' \\ Marta Grodzik' \\ Radosław Piast ${ }^{2}$ \\ Wanvimol Pasanphan ${ }^{3}$ \\ André Chwalibog ${ }^{4}$}

'Department of Animal Nutrition and Biotechnology, Warsaw University of Life Sciences, ${ }^{2}$ Faculty of Chemistry, Warsaw University, Warsaw, Poland; ${ }^{3}$ Department of Materials Science, Faculty of Science, Kasetsart University, Bangkok, Thailand; ${ }^{4}$ Department of Veterinary Clinical and Animal Sciences, University of Copenhagen, Copenhagen, Denmark

Correspondence: André Chwalibog Department of Veterinary Clinical and Animal Sciences, University of Copenhagen, 3 Groennegaardsvej, Frederiksberg, Copenhagen 1870, Denmark

Tel +45 40963573

Fax +4535333020

Email ach@sund.ku.dk
Abstract: In the present study, the toxicity of six different types of carbon nanoparticles (CNPs) was investigated using a chicken-embryo model. Fertilized chicken eggs were divided into the following treatment groups: placebo, diamond NPs, graphite NPs, pristine graphene, small graphene oxide, large graphene oxide, and reduced graphene oxide. Experimental solutions at a concentration of $500 \mu \mathrm{g} / \mathrm{mL}$ were administrated into the egg albumin. Gross pathology and the rate of survival were examined after 5, 10, 15, and 20 days of incubation. After 20 days of incubation, blood samples were collected and the weight of the body and organs measured. The relative ratio of embryo survival decreased after treatment all treatments except diamond NPs. There was no correlation between the rate of survival and the $\zeta$-potential or the surface charge of the CNPs in solution. Body and organ weight, red blood-cell morphology, blood serum biochemical parameters, and oxidative damage in the liver did not differ among the groups. These results indicate that CNPs can remain in blood circulation without any major side effects, suggesting their potential applicability as vehicles for drug delivery or active compounds per se. However, there is a need for further investigation of their properties, which vary depending on production methods and surface functionalization.

Keywords: nanoparticles, diamond, graphite, graphene, toxicity, red blood cells, oxidative stress, surface charge

\section{Introduction}

Carbon nanoparticles (CNPs), such as diamond NPs (DNPs), graphite NPs (GNPs), pristine graphene $(\mathrm{pG})$, graphene oxide $(\mathrm{GO})$, and reduced $\mathrm{GO}(\mathrm{rGO})$, are carbon allotropes that are becoming key materials for various industrial and medical applications, due to their unique combinations of chemical and physical properties. CNPs are largely exploited in biomedicine for cell and tissue imaging, drug delivery, and tissueengineering scaffolds, even though reports regarding their toxicity are still conflicting. ${ }^{1}$ Therefore, the precise characterization of their biocompatibility and toxicity is needed for the safe and responsible exploitation of these materials.

Among CNPs is a distinct group called graphene-family materials (GFMs). The structure of all GFMs is based on graphene, which is a one-atom-thick material consisting of carbon atoms arranged in a honeycomb-lattice structure that leads to exceptional functional and mechanical properties. ${ }^{2}$ Graphene is regarded as the thinnest material in the world, as it is only one carbon atom thick, ${ }^{2}$ although surface areas up to $1 \mathrm{~cm}^{2}$ may be achieved. ${ }^{3}$ The surfaces of GFMs consist of $\mathrm{sp}^{2}$-hybridized carbon atoms, but due to the presence of dangling bonds and the edges of GO and rGO surfaces, $\mathrm{sp}^{3}$ hybridization is present as well. As a consequence, the nature of interactions between biological molecules and GFMs likely depends on the $\mathrm{sp}^{2}$ - or $\mathrm{sp}^{3}$-hybridization 
state of the carbon. ${ }^{4,5}$ Therefore, it is very important to investigate and compare the impact of different GFMs in biological models.

There are different production methods for CNPs. The major fabrication methods include detonation and explosion-induced high-pressure techniques for $\mathrm{DNPs}^{6-8}$ or heat treatment above $1,000^{\circ} \mathrm{C}$ for GNP production. ${ }^{8}$ Micromechanical cleavage, chemical vapor deposition, oxidation, exfoliation, and reduction of graphite are used for GFM manufacturing. ${ }^{9}$ The method by which CNPs are synthesized directly affects their physicochemical properties and in turn their potential toxicity in biological systems. ${ }^{10,11}$ Therefore, one of the objectives of the present study was to evaluate the influence of the synthesis method, size, shape, and surface characteristics of CNPs on chicken-embryo development.

Chicken embryos occupy a privileged place among animal models used in developmental and toxicity studies, and have also contributed significantly to immunology, genetics, virology, cancer, and cell biology. ${ }^{12,13}$ Rapid development and the fact that embryos are readily accessible for visualization and experimental manipulation are just some of the characteristics that have made them the vertebrate model of choice for more than two millennia. ${ }^{14}$ The chicken-embryo model permits controlled administration of substances and direct observation of embryonic development. ${ }^{13}$ Embryonic development is complete by the time of hatching at 21 days, as described in Hamburger-Hamilton (HH) stages. ${ }^{15}$ The early stages of chickens' rapid embryonic growth provide a sensitive model for investigating the potential toxic effects on body weight, organ development, and oxidative damage. The objective of this study was to evaluate the toxicity of different types of CNPs administered at the beginning of embryogenesis in the chicken-embryo model.

There have been several reports in the literature demonstrating the toxicity of different CNPs in various biological embryo models, such as chicken, ${ }^{16-19}$ zebrafish, ${ }^{20-25}$ and Xenopus laevis. ${ }^{26,27}$ For example, carbon nanotubes inhibited angiogenesis of the chorioallantoic membrane in chicken embryos and caused death before day 12 of the incubation period. ${ }^{19}$ Zebrafish embryos treated with nanodiamond (ND) were malformed in a dose-dependent manner. ${ }^{28}$ However, no toxic effects were observed for fluorescent ND. ${ }^{21}$ In the case of GO, dose-dependent gross morphological defects, hatching delays, and death of zebrafish embryos were observed. ${ }^{20,23,24}$ In in vivo experiments with $X$. laevis embryos, ND was highly embryotoxic and teratogenic. ${ }^{27}$ Nevertheless, the investigations described only focused on particular nanomaterials without comparing the biological effects of different carbon allotropes manufactured by different methods and with diverse physicochemical properties.

In our previous study, ${ }^{16} \mathrm{pG}$ had harmful effects on brain development in chicken embryos. Furthermore, pG, GO, and rGO caused mitochondrial damage and an atypical hepatocyte ultrastructure in chicken embryos. ${ }^{17}$ However, neither study reported dose-dependent toxicity. DNPs do not affect embryo development, although they form deposits in the liver tissue. ${ }^{18}$

We hypothesized that the various synthesis methods and physicochemical properties of CNPs may potentially impact their toxicity profiles in a fast-growing, highly sensitive organism. To evaluate further the potential risks that CNPs pose to human health, the toxic effects of CNPs on gross pathology, red blood cell (RBC) morphology, and liver biochemistry and oxidative damage were investigated in this study.

\section{Materials and methods Nanoparticles}

DNPs, GNPs, and pG were purchased from SkySpring Nanomaterials (Houston, TX, USA). Small and large GO flakes (sGO and 1GO, respectively) and rGO were synthesized at the Institute of Electronic Materials Technology, Warsaw, Poland. Spherical DNPs were produced by the detonation method, and ranged in size from 3 to $4 \mathrm{~nm}$. According to the producer, the purity of the material was $>95 \%$, with a specific surface area of $\sim 282 \mathrm{~m}^{2} / \mathrm{g}$. GNPs were produced by the explosion method, and ranged in size from 3 to $4 \mathrm{~nm}$. The purity of the material was $93 \%$, with a specific surface area of $540-650 \mathrm{~m}^{2} / \mathrm{g}$. pG powder was derived from natural flakes by liquid-phase exfoliation of graphite. According to the producer, the purity of this material was $>99.5 \%$. It had a specific surface area of $120-150 \mathrm{~m}^{2} / \mathrm{g}$, and the thickness of the particles was $1-5 \mathrm{~nm}$, with an average flake diameter of $4 \mu \mathrm{m}$.

IGO flakes were prepared using natural graphite flakes by a modified Hummers method, as described previously ${ }^{4}$ (purchased from Asbury Carbons, Asbury, NJ, USA). In order to prepare rGO, a water suspension with $50 \mathrm{mg}$ of $1 \mathrm{GO}$ was used as described in our previous report. ${ }^{4}$ sGO flakes were prepared by a modified Hummers method, as described previously, ${ }^{29}$ and ranged in size from 8 to $25 \mathrm{~nm}$.

NP powders were resuspended in water for injection (WFI; Aqua Pro injection; Polpharma, Starogard Gdański, Poland) to a concentration of $500 \mu \mathrm{g} / \mathrm{mL}$ and sonicated at $550 \mathrm{~W} / \mathrm{m}^{2}$ for 1 hour in an ultrasonic bath (Sonorex Super RK 514H; Bandelin Electronic, Berlin, Germany). 


\section{Visualization of nanoparticles}

CNPs were inspected using a transmission electron microscopy (TEM) at $80 \mathrm{keV}$ (JEM-2000EX; JEOL, Tokyo, Japan) with a Morada 11 megapixel camera (Olympus Corporation, Tokyo, Japan). TEM samples of CNP suspensions $(50 \mu \mathrm{g} / \mathrm{mL})$ were prepared by placing droplets of hydrocolloids onto formvar-coated copper grids (Agar Scientific Ltd, Stansted, UK). Immediately after the droplets had air-dried, grids were inserted into the TEM instrument. Each test was performed in triplicate. The macroscopic structure of CNPs powder was visualized using a D7000 digital camera with an AF-S Micro-Nikkor $105 \mathrm{~mm}$ f/2.8G IF-ED VR lens (Nikon, Tokyo, Japan).

\section{$\zeta$-Potential measurements}

The $\zeta$-potentials of CNPs resuspended in WFI were measured by the laser dynamic scattering electrophoretic method using the Smoluchowski approximation with a Zetasizer Nano ZS90 (Malvern Instruments, Malvern, UK). Each sample was measured after stabilization at $25^{\circ} \mathrm{C}$ for 120 seconds. Each measurement was repeated three times.

\section{Spectroscopic characterization}

The content of chemical bonds was identified from Fourier transform infrared (FTIR) spectra and recorded on a Tensor 27 FTIR spectrometer (Bruker, Billerica, MA, USA), with 32 scans at a resolution of $2 \mathrm{~cm}^{-1}$ in the frequency range $650-4,000 \mathrm{~cm}^{-1}$. FTIR direct-transmittance spectroscopy $(\mathrm{KBr})$ was used to indicate the degree to which oxygen groups were removed, and the IR absorption of water from the air was mostly eliminated. CNP samples were measured as a pastille mixed with $\mathrm{KBr}$ and compacted under high pressure ( $>10 \times$ atmospheric pressure). Each measurement was recorded immediately and repeated three times.

\section{Embryo model}

\section{Embryo maintenance and nanoparticle administration}

According to the Polish legal regulations regarding animal experiments (DzU 2015 poz 266), there is no need to submit an application to the local ethics committee for studies conducted with chicken embryos. According to this act, a chicken embryo is not defined as an animal.

Fertilized eggs $(\mathrm{n}=210,56 \pm 2.1 \mathrm{~g})$ from Ross Line 308 hens (Gallus gallus) were obtained from a commercial hatchery (Marylka, Poland), stored for 1 day at $12^{\circ} \mathrm{C}$, and then incubated under standard conditions. Prior to incubation, the eggs were weighed and randomly divided into seven groups ( $\mathrm{n}=30$ eggs per group). The placebo group was injected with WFI alone, while each experimental group was treated with CNPs resuspended in WFI at a concentration of $500 \mu \mathrm{g} / \mathrm{mL}$. The experimental solutions were given in ovo by injecting $0.3 \mathrm{~mL}$ of each solution into the albumin (at twothirds the egg's height from the blunt end), using a sterile $1 \mathrm{~mL}$ tuberculin syringe. Injection holes were sterilized, and the eggs were then incubated at $37^{\circ} \mathrm{C}$ with $70 \%$ humidity and turned once per hour.

\section{Evaluation of embryotoxicity}

After 5, 10, 15, and 20 days of incubation, the eggs were opened and embryonic development evaluated. At day 20, the embryos were weighed together with the yolk sack, killed by decapitation, and blood samples from the jugular vein were collected. The morphology of the embryos was examined according to the HH stages, ${ }^{15}$ and a photo of each stage was taken using a digital camera (Pen Lite E-P16; Olympus, Tokyo, Japan). The chosen organs (brain, heart, liver, spleen, and kidney) were dissected and weighed. Samples of the liver were fixed in liquid nitrogen and stored at $-80^{\circ} \mathrm{C}$ for further analysis.

\section{Red blood-cell morphology}

Peripheral blood smears were made with $5 \mu \mathrm{L}$ of blood using the two-slide wedge technique, air-dried, and stained by the Pappenheim method with May-Grünwald and Giemsa solutions (Sigma-Aldrich, Saint Louis, MO, USA). Monolayers of peripheral blood smears were examined at a magnification of $1,000 \times$ under light microscopy (DM750; Leica Microsystems, Wetzlar, Germany) connected to a digital camera with LAS EZ version 2.0 software (Leica). Approximately half the erythrocytes were connected to one another on the slide. Avian erythrocytes were evaluated for cellular size, shape, color, nuclear size, nuclear shape and color, and presence/absence of cellular inclusions.

\section{Blood serum biochemistry}

The rest of the blood samples were placed into tubes with a clot activator (EquiMed, Morgan Hill, CA, USA) for serum determinations. All biochemical parameters were assessed using a Miura One clinical chemistry analyzer (ISE, Guidonia, Italy), and the reagents were purchased from Pointe Scientific (Canton, MI, USA). Blood collected in the tubes with a coagulation activator was centrifuged at $3,800 \mathrm{~g}$ for 8 minutes at $4^{\circ} \mathrm{C}$ to isolate hemolysis-free serum. Biochemistry of the hemolysis-free serum was assessed via standard laboratory procedures. The following components 
were examined: aspartate aminotransferase, alanine aminotransferase, alkaline phosphatase, glucose, creatinine, blood urea nitrogen, total protein, albumin, lactate dehydrogenase, and triglycerides.

\section{Liver-tissue homogenate preparation}

Tissue homogenates were prepared in the buffers provided by the manufacturer (Abcam, Cambridge, UK). Liver tissue was homogenized using a TissueLyser LT (Qiagen NV, Venlo, the Netherlands) with a prefrosted adapter at $50 \mathrm{~Hz}$ for 10 minutes, followed by centrifugation at $13,000 \mathrm{~g}$ for 10 minutes at $4^{\circ} \mathrm{C}$ (Sorvall ST16; Thermo Fisher Scientific, Waltham, MA, USA). The supernatant ("homogenate") was collected for analysis.

\section{Lipid peroxidation}

Quantification of lipid peroxidation in liver tissue was performed using a lipid-peroxidation malondialdehyde (MDA)-assay kit (Abcam). Lipid peroxidation forms MDA and 4-hydroxynonenal as natural byproducts. MDA in the sample reacts to form an adduct with thiobarbituric acid, which can be quantified colorimetrically $(\lambda=532 \mathrm{~nm})$. The minimum detectable amount of MDA by this colorimetric method is $1 \mathrm{nmol} / \mathrm{well}$.

The homogenate was prepared in lysis buffer containing butylated hydroxytoluene provided by the manufacturer (20 mg of liver tissue per $300 \mu \mathrm{L}$ of MDA lysis buffer). Further steps were performed in accordance with the manufacturer's protocol, including an additional step of filtering samples through a $0.22 \mu \mathrm{m}$ syringe filter to reduce turbidity. Measurements were performed with an Infinite ${ }^{\circledR}$ 200 Pro microplate reader with I-Control ${ }^{\mathrm{TM}}$ software (Tecan, Männedorf, Switzerland).

\section{Statistical analysis}

Data were evaluated by monofactorial analysis of variance. Differences between groups were tested by the multiplerange Tukey's test using Statgraphics Centurion version 15 (Statpoint Technologies, Warrenton, VA, USA). Differences with $P<0.05$ were considered significant.

\section{Results}

\section{Characterization of nanoparticles and their colloids}

The six forms of CNPs differed in size (Table 1), flake shape, and powder appearance (Figure 1). TEM images show examples of average CNP flakes. DNPs (Figure 1A) and GNPs (Figure 1C) were spherical, while pG (Figure 1E), sGO (Figure 1G), and rGO (Figure 1K) had irregular forms.
Table I Summary of the physical and chemical properties of NPs

\begin{tabular}{|c|c|c|c|c|}
\hline$\overline{\text { NP }}$ & Shape & $\begin{array}{l}\text { Average } \\
\text { size, } \mathrm{nm}\end{array}$ & 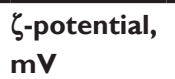 & Surface chemical bonds \\
\hline DNPs & Spherical & $3-4$ & $-21.40 \pm 1.153$ & $\begin{array}{l}-\mathrm{O}-\mathrm{H},-\mathrm{C}-\mathrm{N},-\mathrm{C}=\mathrm{O}, \\
-\mathrm{C}-\mathrm{O}-\mathrm{C},-\mathrm{COOH}\end{array}$ \\
\hline GNPs & Spherical & $3-4$ & $35.57 \pm 0.603$ & $\begin{array}{l}-\mathrm{O}-\mathrm{H},-\mathrm{C}=\mathrm{C},-\mathrm{C}-\mathrm{O}-\mathrm{C} \\
-\mathrm{C}-\mathrm{O}\end{array}$ \\
\hline pG & Irregular & 4,000 & $4.15 \pm 0.645$ & $-\mathrm{O}-\mathrm{H},-\mathrm{C}=\mathrm{C},-\mathrm{C}=\mathrm{O}$ \\
\hline sGO & Irregular & $8-25$ & $-4.49 \pm 0.159$ & $\begin{array}{l}-\mathrm{O}-\mathrm{H},-\mathrm{C}=\mathrm{C},-\mathrm{C}=\mathrm{O}, \\
-\mathrm{C}-\mathrm{O}\end{array}$ \\
\hline IGO & Filmlike & 1,270 & $-16.73 \pm 0.404$ & $\mathrm{O}-\mathrm{H}, \mathrm{C}=\mathrm{C},-\mathrm{C}-\mathrm{O}-\mathrm{C}, \mathrm{C}-\mathrm{O}$ \\
\hline rGO & Irregular & 2,530 & $-20.93 \pm 0.379$ & $\mathrm{O}-\mathrm{H}, \mathrm{C}=\mathrm{C},-\mathrm{C}-\mathrm{O}-\mathrm{C}, \mathrm{C}-\mathrm{O}$ \\
\hline
\end{tabular}

Notes: Shape was estimated upon analysis of transmission electron microscopy. $\zeta$-potential was measured by Zetasizer. Values are presented as mean \pm standard deviation. The content of chemical bonds was identified by Fourier transform infrared spectra analysis.

Abbreviations: NP, nanoparticles; DNPs, diamond nanoparticles; GNPs, graphite nanoparticles; $\mathrm{PG}$, pristine graphene; sGO, small graphene oxide; IGO, large graphene oxide; rGO, reduced graphene oxide.

The only major difference in appearance was 1GO, which mainly formed a large filmlike layer (Figure 1L). The shape of all GFMs was irregular with sharp edges, forming rough structures. The thickness of $\mathrm{pG}, 1 \mathrm{GO}$, and rGO was in the nanoscale; however, the surface was not. Most of the GFM flakes were single layers or a few layers thick with surface diameters of 1-4 $\mu \mathrm{m}$ (Table 1), except for sGO, which was significantly smaller. The small size of sGO is related directly to its production method and the precursor material: small GNP particles (3-4 nm). The appearance of each NP powder differed in color, structure, and fragmentation-grade level. DNP powder was light brown (Figure 1B), while GNP powder was deep dark gray (Figure 1D), but both were mostly fine-grained. $p G$ powder was dark gray, and its texture looked like easy-to-separate cotton candy (Figure 1F). sGO powder was dark brown (Figure 1H), while $1 \mathrm{GO}$ powder was light brown and iridescent (Figure 1J). The texture of these two GO powders also varied, sGO powder being mostly as finegrained as its precursor, while 1GO formed small leaflike structures that were facile to deform but simultaneously ultralight. rGO powder was the darkest and had the finest grains (Figure 1L).

The $\zeta$-potential, which is an indicator of colloid stability and surface charge, was lowest for $\mathrm{pG}(4.15 \mathrm{mV})$ and sGO $(-4.49 \mathrm{mV})$ and highest for GNPs $(35.57 \mathrm{mV})$ (Table 1). For DNPs, 1GO, and rGO, stability levels were in between, with mean values of $-21.4,-16.73$, and $-20.93 \mathrm{mV}$, respectively.

Figure 2 shows typical FTIR spectra obtained for the CNPs in this study. The most characteristic feature for all CNPs was the broad, intense band at 3,430-3,444 $\mathrm{cm}^{-1}$, which can be attributed to the $\mathrm{O}-\mathrm{H}$ stretching vibrations of hydroxyl groups in adsorbed water molecules, structural $\mathrm{OH}$ groups, and 

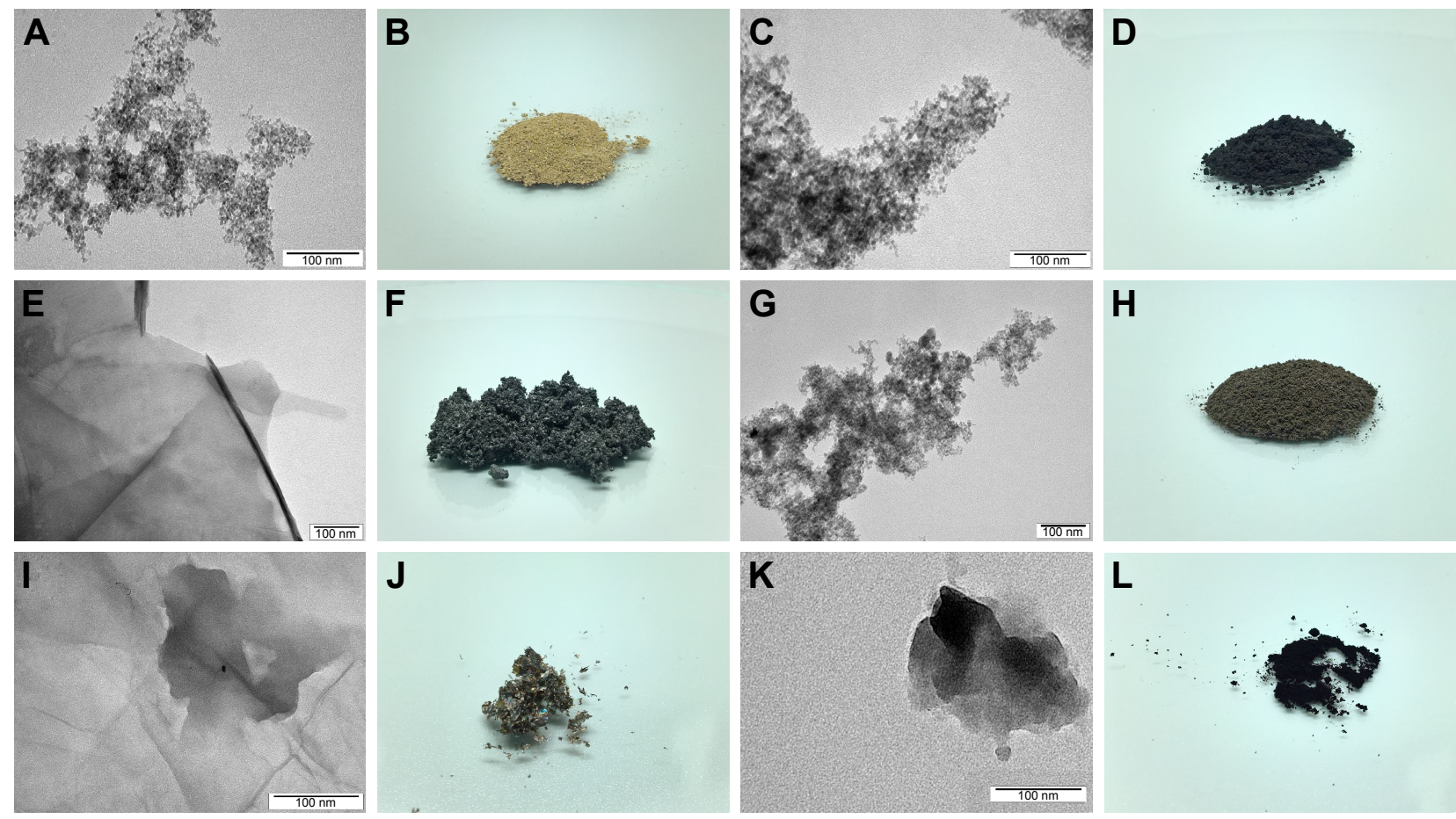

Figure I Nanoparticles were visualized using transmission electron microscopy (A, C, E, G, I, K) and a digital camera (B, D, F, H, J, L).

Note: Nanoparticles of diamond (A, B), graphite (C, D), pristine graphene (E, F), small graphene oxide (G, H), large graphene oxide (I, J), and reduced graphene oxide (K, L).

carboxylic acids. ${ }^{30}$ In the GNP and pG groups, we observed asymmetric bonds of alkyl groups at 2,917-2,920 $\mathrm{cm}^{-1}$, which also corresponds to $\mathrm{O}-\mathrm{H}$ stretching vibrations. ${ }^{31}$ Skeletal vibrations from unoxidized graphitic domains were observed at 1,623-1,632 $\mathrm{cm}^{-1}$ for most of the CNPs except rGO, which peaked at $1,589 \mathrm{~cm}^{-1}$. $\mathrm{pG}$ also had an additional peak for $\mathrm{C}=\mathrm{C}$ bonds at $1,572 \mathrm{~cm}^{-1}$. These peaks correspond to the $\mathrm{sp}^{2}$ character of CNPs $;{ }^{32}$ therefore, the rest of the chemical bonds corresponded to $\mathrm{sp}^{3}$-hybridization structures in CNPs, which occur due to dangling bonds on the sharp edges of nanomaterials, as well as from oxidative functional groups on the $\mathrm{GO} / \mathrm{rGO}$ surface. ${ }^{33}$ With regard to this research, $\mathrm{sp}^{3}$-hybridized bonds are highly important, because they contribute to interactions between CNPs and biological systems. ${ }^{4} \mathrm{ND}, \mathrm{pG}$, and sGO also had peaks at $1,720-1,757 \mathrm{~cm}^{-1}$, due to $\mathrm{C}=\mathrm{O}$ stretching vibrations from carbonyl and carboxylic groups. ${ }^{34} \mathrm{ND}$, GNPs, IGO, and rGO also had peaks at 1,239-1,261 $\mathrm{cm}^{-1}$ caused by $\mathrm{C}-\mathrm{O}-\mathrm{C}$ stretching vibrations from epoxy-functional groups. ${ }^{30,35}$ Aside from $\mathrm{pG}$, the rest of the CNPs had $\mathrm{C}-\mathrm{O}$ stretching vibrations at $1,092-1,114 \mathrm{~cm}^{-1}$.

\section{Evaluation of embryotoxicity}

The relative rate of survival of embryos was moderate and decreased after treatment with CNPs in almost all experimental groups, except for DNPs (Table 2). The relative rate of survival for sGO and its precursor GNPs was almost similar.
However, the survival for $\mathrm{rGO}$ and its precursor $1 \mathrm{GO}$ differed, which might be directly related to the presence of functional groups on their surfaces.

Macroscopic visualization indicated that all chicken embryos developed normally in accordance with $\mathrm{HH}$ stages in the DNP, GNP, pG, sGO, and rGO groups (Figure 3). However, in the placebo and 1GO groups, two chicken embryos developed with some abnormalities, which sometimes occur during incubation. We suppose that these deformed individuals would not hatch. After 20 days of incubation (HH stages 44-45), chickens were completely developed and yolk sacs almost totally enclosed by the body cavity. Only in the rGO group were yolk sacs only partially enclosed by the body cavity. Statistical analysis of embryo weight showed no significant differences among the groups. Similarly, weights of liver, heart, brain, spleen, and kidney of embryos at day 20 did not differ significantly among the groups (Table 3 ).

\section{Red blood-cell morphology}

Blood smears showed no symptoms of RBC inflammation (Figure 4) in any group. Blood films were stained with MayGrünwald and Giemsa solution, and typically the nucleus stained purple, while the cytoplasm appeared pink with a uniform texture. Single erythrocytes were deformed, due to the mechanical stress applied during slide preparation; these deformities are common artifacts and not related to CNP 

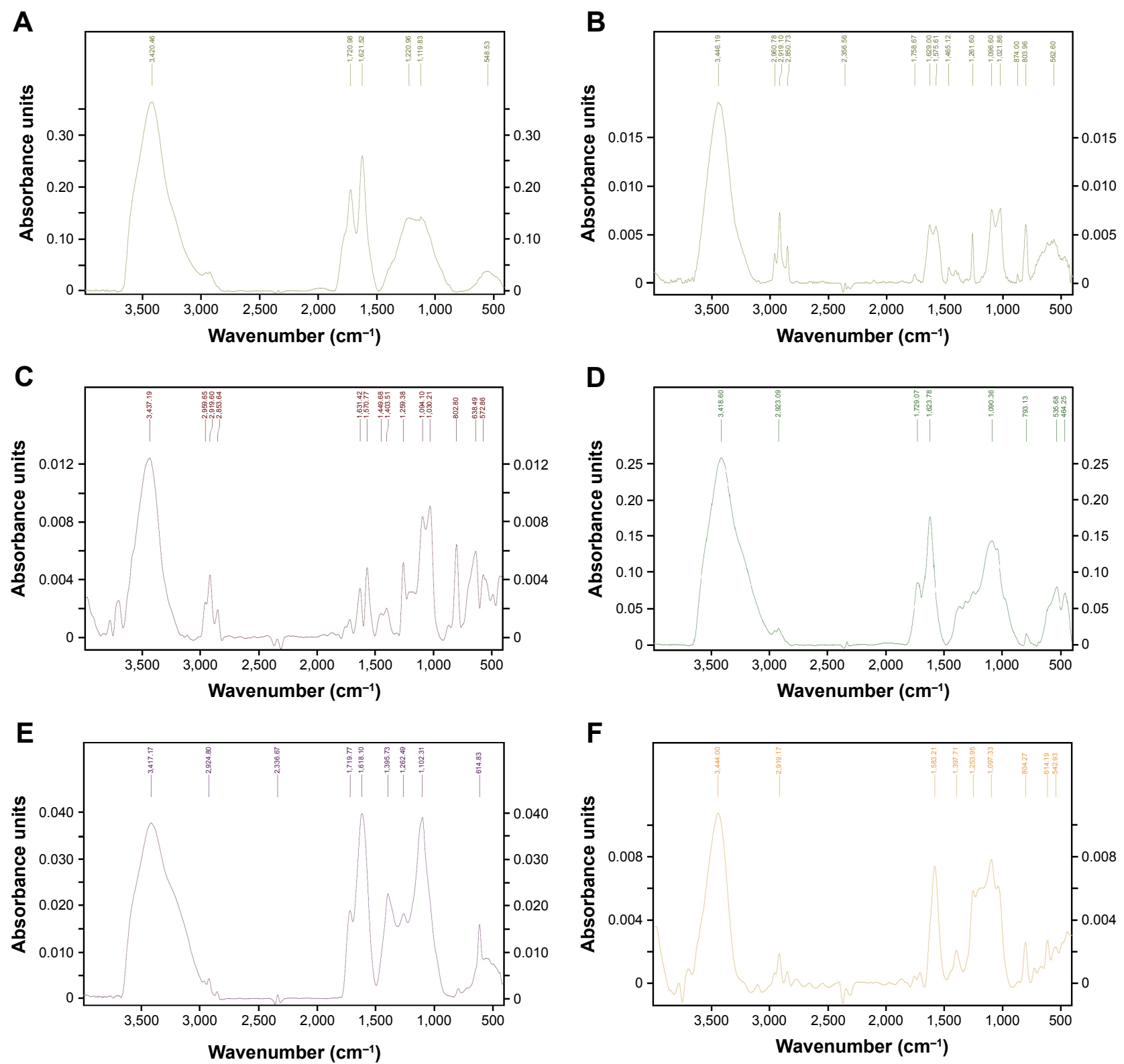

Figure 2 Room-temperature Fourier transform infrared spectra.

Note: Nanoparticles of diamond (A), graphite (B), pristine graphene (C), small graphene oxide (D), large graphene oxide (E), and reduced graphene oxide (F).

Table 2 Chicken-embryo direct rate of survival and relative rate of survival

\begin{tabular}{lll}
\hline Group & Direct rate of survival (\%) & Relative rate of survival (\%) \\
\hline PI & 80 & 100 \\
DNPs & 81 & 101 \\
GNPs & 71 & 89 \\
PG & 74 & 92.5 \\
sGO & 70 & 87.5 \\
IGO & 64 & 80 \\
rGO & 76 & 95 \\
\hline
\end{tabular}

Note: Relative ratio of survival counted by dividing direct rate of survival of investigated sample per direct rate of survival of placebo group and then multiplying by $100 \%$.

Abbreviations: PI, placebo; DNPs, diamond nanoparticles; GNPs, graphite nanoparticles; NP, nanoparticle; $\mathrm{PG}$, pristine graphene; sGO, small graphene oxide; IGO, large graphene oxide; rGO, reduced graphene oxide. treatment. Evaluation of RBCs by light microscopy demonstrated that CNPs had no harmful effects on their morphology. Cell membranes were completely intact and retained their ideal density, the oval shape of nucleated cells was preserved, and cells kept their biconcavity. The size of RBCs ranged from 12.7 to $15.23 \mu \mathrm{m}$ in length and 6.34 to $7.61 \mu \mathrm{m}$ in width for all groups, except rGO, where the cells were more rounded than oval and also smaller (10.16-12.7 $\mu \mathrm{m}$ length). In all groups, cell nuclei had a regular oval shape and were found in the middle of the cell with agglomerated reticular material that appeared as indentions, protrusions, and constrictions. The average length of the nucleus was 

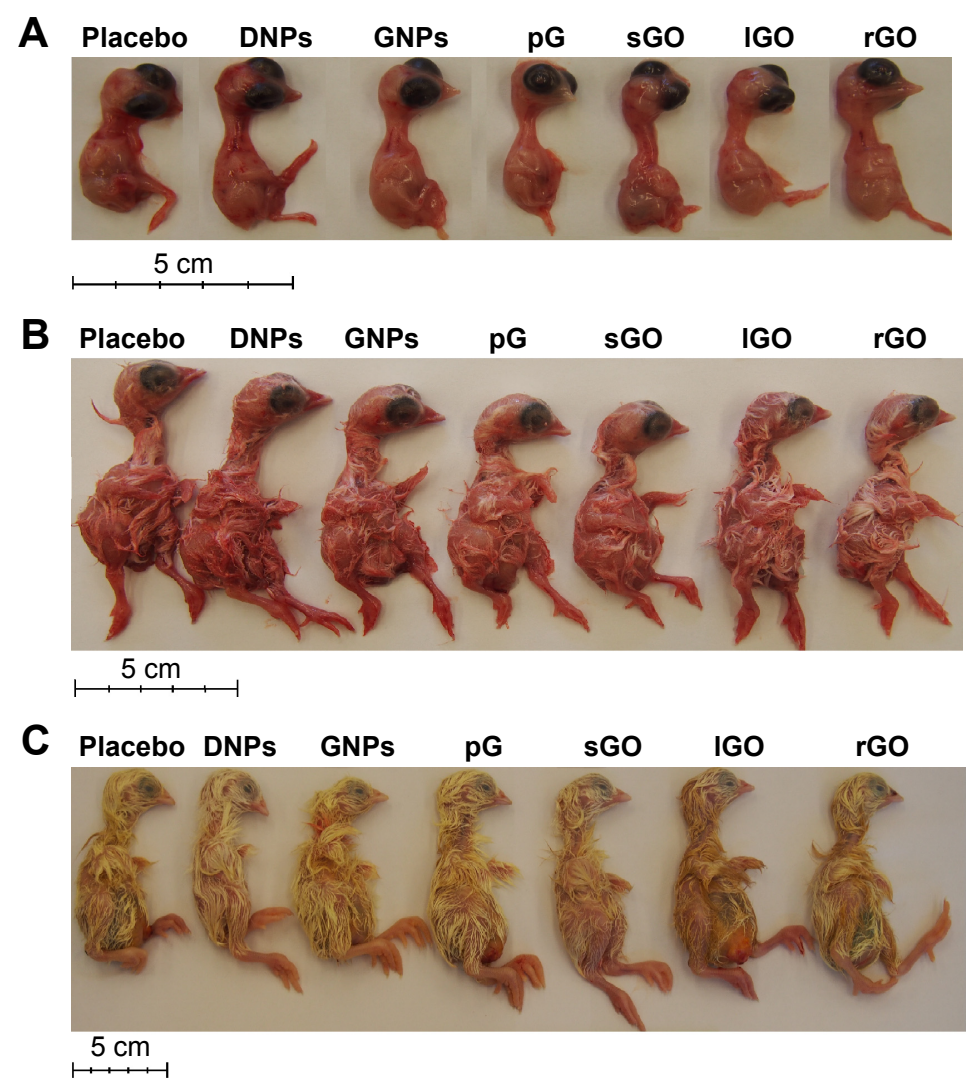

Figure 3 Chicken-embryo development after 10 (A), 15 (B), and 20 (C) days of incubation.

Abbreviations: DNPs, diamond nanoparticles; GNPs, graphite nanoparticles; pG, pristine graphene; sGO, small graphene oxide; IGO, large graphene oxide; rGO, reduced graphene oxide.

$3.81-5.71 \mu \mathrm{m}$ and its width was $2.64 \mu \mathrm{m}$. Nuclei of RBCs in the $\mathrm{sGO}$ group were slightly bigger than in the other groups (5.75-6.34 $\mu \mathrm{m}$ length and 2.64-3.17 $\mu \mathrm{m}$ width). For all groups, there were no cellular inclusions in the erythrocytes, which were normal in size and stained correctly.

\section{Blood serum biochemistry}

None of the biochemical indices measured in the blood serum of the embryos showed significant effects from the treatment
(Table 4). Based on Mazurkiewicz, ${ }^{36}$ all biochemical indices were within the reference range.

\section{Lipid oxidation in the liver}

There were no significant differences $(P<0.05)$ between the treatment groups (DNPs, GNPs, $\mathrm{pG}, \mathrm{sGO}, 1 \mathrm{GO}, \mathrm{rGO}$ ) and the placebo group. The level of MDA in all the groups was similar, indicating that there was no oxidative damage to the embryo livers induced by CNP administration (Figure 5).

Table 3 Mean embryo body and organ weight

\begin{tabular}{lllllll}
\hline Group & $\begin{array}{l}\text { Embryo body } \\
\text { weight }(\mathrm{g})\end{array}$ & $\begin{array}{l}\text { Brain }(\mathrm{g} / \mathrm{I00} \mathrm{g} \\
\text { of body mass) }\end{array}$ & $\begin{array}{l}\text { Heart }(\mathrm{g} / \mathrm{I00} \mathrm{g} \\
\text { of body mass) }\end{array}$ & $\begin{array}{l}\text { Spleen }(\mathrm{g} / \mathrm{I00} \mathrm{g} \\
\text { of body mass) }\end{array}$ & $\begin{array}{l}\text { Kidney (g/100 g } \\
\text { of body mass) }\end{array}$ & $\begin{array}{l}\text { Liver }(\mathrm{g} / \mathrm{I00} \mathrm{g} \\
\text { of body mass) }\end{array}$ \\
\hline PI & $46.39 \pm 2.572$ & $1.83 \pm 0.153$ & $0.42 \pm 0.042$ & $0.03 \pm 0.018$ & $0.07 \pm 0.011$ & $1.3 \pm 0.214$ \\
DNPs & $44.72 \pm 5.675$ & $2.01 \pm 0.321$ & $0.46 \pm 0.066$ & $0.03 \pm 0.018$ & $0.07 \pm 0.019$ & $1.58 \pm 0.221$ \\
GNPs & $44.82 \pm 2.462$ & $1.95 \pm 0.228$ & $0.49 \pm 0.07$ & $0.04 \pm 0.016$ & $0.07 \pm 0.017$ & $1.50 \pm 0.438$ \\
PG & $48.43 \pm 3.368$ & $1.83 \pm 0.159$ & $0.45 \pm 0.064$ & $0.02 \pm 0.008$ & $0.08 \pm 0.032$ & $1.27 \pm 0.267$ \\
sGO & $48.46 \pm 3.159$ & $1.63 \pm 0.205$ & $0.43 \pm 0.034$ & $0.03 \pm 0.004$ & $0.06 \pm 0.006$ & $1.26 \pm 0.124$ \\
IGO & $38.44 \pm 9.043$ & $1.99 \pm 0.74$ & $0.54 \pm 0.176$ & $0.03 \pm 0.008$ & $0.08 \pm 0.016$ & $1.57 \pm 0.84$ \\
rGO & $44.53 \pm 3.757$ & $1.83 \pm 0.384$ & $0.43 \pm 0.058$ & $0.02 \pm 0.013$ & $0.08 \pm 0.035$ & $1.37 \pm 0.322$ \\
$P$-value & 0.114 & 0.911 & 0.544 & 0.408 & 0.846 & 0.784 \\
\hline
\end{tabular}

Note: Mean values of multiple determinations $(n=6) \pm$ standard deviation.

Abbreviations: PI, placebo; DNPs, diamond nanoparticles; GNPs, graphite nanoparticles; NP, nanoparticle; pG, pristine graphene; sGO, small graphene oxide; IGO, large graphene oxide; rGO, reduced graphene oxide. 


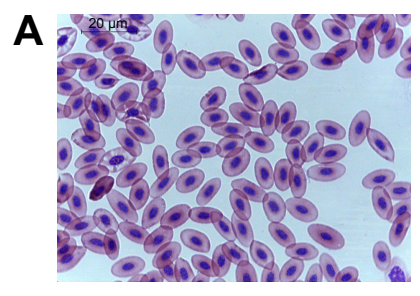

E

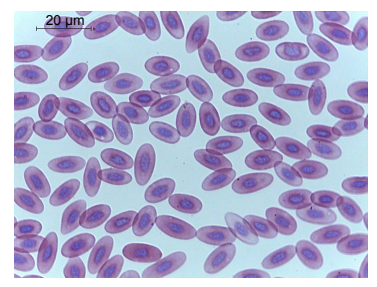

B

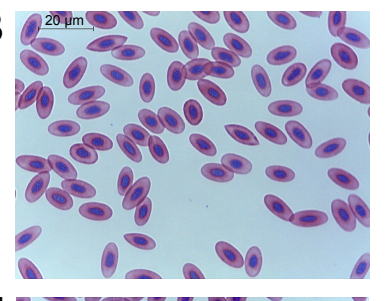

$F$

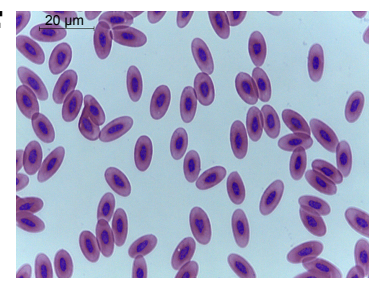

C
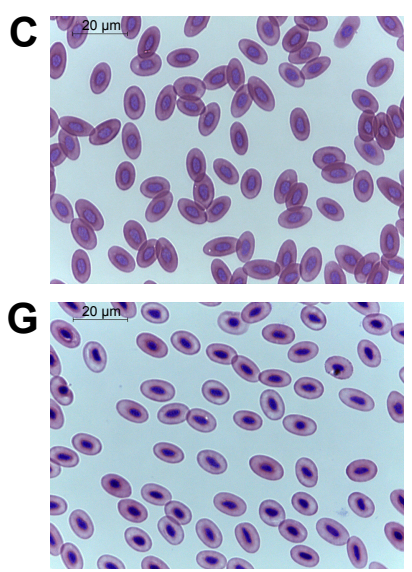

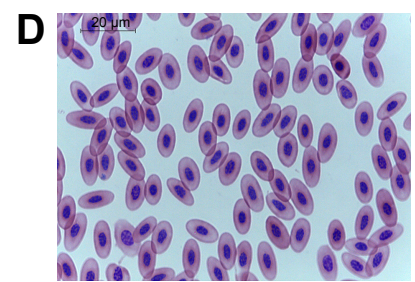

n. 6020

Figure 4 Red blood-cell morphology by light microscopy.

Note: Placebo $(\mathbf{A})$ and nanoparticles of diamond $(\mathbf{B})$, graphite $(\mathbf{C})$, pristine graphene $(\mathbf{D})$, small graphene oxide $(\mathbf{E})$, large graphene oxide $(\mathbf{F})$, and reduced graphene oxide $(\mathbf{G})$.

\section{Discussion}

The toxicity of multiple CNPs was investigated at $500 \mu \mathrm{g} / \mathrm{mL}$, as it has been demonstrated that doses of GFMs $>5,000 \mu \mathrm{g} / \mathrm{mL}$ increase mortality rates. ${ }^{17}$ This is the same dose that was administrated to laboratory rats in our previous studies..$^{29,37}$ The CNPs were resuspended in WFI, which is commonly used for diluting or dissolving drugs for parenteral injection (including intravenous, intra-arterial, intramuscular, or subcutaneous injections). ${ }^{38}$ WFI properties differ from Milli-Q water, and might explain the disparity between this work and previous research on GFM embryotoxicity. ${ }^{16,17}$ Firstly, differences can be observed in the rate of survival for placebo groups: in the present study, the survival rate was $80 \%$ (Table 2), whereas studies using Milli-Q water have reported rates $>90 \% .^{16,17}$ This result indicates that WFI could affect the fluid and electrolyte balance in egg albumin. However, dissolving CNPs in WFI increased the relative percentage of embryos that survived CNP treatment compared to studies with CNPs dissolved in Milli-Q water. ${ }^{16,17}$

According to Szmidt et al, ${ }^{17}$ lower concentrations (50 and $500 \mu \mathrm{g} / \mathrm{mL}$ ) of graphene penetrate the embryo more efficiently than higher concentrations, due to different NPdispersion levels. These results were explained by the natural tendency of CNPs to agglomerate when they are coated by the albumin proteins that surround the embryo. ${ }^{16}$ In the present study, we also administrated CNPs to the egg albumin, which gets progressively consumed by the embryo during the development process and is ultimately fully absorbed, ${ }^{36}$ ensuring that the whole dose was delivered during embryogenesis. Furthermore, self-assembly of CNPs with albumin amino acids by noncovalent bonds is very efficient, ${ }^{39,40}$ implying that CNPs can be effectively transported into embryos.

Although the survival rate decreased in CNP-treated groups relative to the placebo group, except for DNPs (Table 2), macroscopic morphology of the bodies of 5-, 10-, 15-, and 20-day-old embryos (Figure 3), body weights, and the weights of organs (Table 3 ) did not differ between the placebo and treatment groups. These results are consistent with previous studies demonstrating that $\mathrm{DNPs}^{18}$ and $\mathrm{pG}^{16,17}$ are not harmful to embryonic development.

Since the blood-circulation system is used to transport CNPs from the egg albumin to the embryos, it is crucial to

Table 4 Mean blood serum biochemical parameters

\begin{tabular}{|c|c|c|c|c|c|c|c|c|c|c|}
\hline Group & $\begin{array}{l}\text { AST } \\
\text { (IU/L) }\end{array}$ & $\begin{array}{l}\text { ALT } \\
\text { (IU/L) }\end{array}$ & $\begin{array}{l}\text { ALP } \\
\text { (IU/L) }\end{array}$ & $\begin{array}{l}\text { Glucose } \\
\text { (mg/dL) }\end{array}$ & $\begin{array}{l}\text { Creatinine } \\
(\mathrm{mg} / \mathrm{dL})\end{array}$ & $\begin{array}{l}\text { BUN } \\
(\mathrm{mg} / \mathrm{dL})\end{array}$ & $\begin{array}{l}\text { TP } \\
\text { (g/L) }\end{array}$ & $\begin{array}{l}\text { Albumin } \\
\text { (g/L) }\end{array}$ & LDH (U/L) & $\begin{array}{l}\text { TGs } \\
(\mathrm{mg} / \mathrm{dL})\end{array}$ \\
\hline $\mathrm{PI}$ & $|83.6 \pm 45.8|$ & $15.3 \pm 4.73$ & $1,680.6 \pm 265.98$ & $230.4 \pm 17.09$ & $0.39 \pm 0.07$ & $28 \pm 1.31$ & $16 \pm 2.43$ & $13 \pm 0.06$ & $897.9 \pm 165.09$ & $84.2 \pm 23.76$ \\
\hline DNPs & $238.5 \pm 38.73$ & $17 \pm 4.69$ & $1,683 \pm 233.44$ & $247.9 \pm 12.29$ & $0.47 \pm 0.06$ & $20.9 \pm 1.5$ & $14 \pm 1.73$ & $9.7 \pm 3.79$ & $810.1 \pm 240.03$ & $52.9 \pm 20.39$ \\
\hline GNPs & $240.1 \pm 54.94$ & $13.8 \pm 5.59$ & I,74I. $2 \pm 63$ I.23 & $248.4 \pm 14.64$ & $0.36 \pm 0.06$ & $25.7 \pm 0.7$ I & $|5.5 \pm 0.7|$ & $7 \pm 0.03$ & $817.1 \pm 138.38$ & $38.9 \pm 7.42$ \\
\hline pG & $176.2 \pm 34.35$ & $11.3 \pm 8.62$ & $|, 740.5 \pm 743.9|$ & $208.1 \pm 39.73$ & $0.46 \pm 0.05$ & $23.1 \pm 3.79$ & $12.7 \pm 3.79$ & $6.3 \pm 1.53$ & $693.2 \pm 160.68$ & $44.2 \pm 24.02$ \\
\hline sGO & $212.2 \pm 65.9$ & $7.4 \pm 2.33$ & $1,061.9 \pm 1,069.15$ & $235.8 \pm 5.09$ & $0.4 \pm 0.11$ & $25.6 \pm 3.53$ & $16.5 \pm 3.53$ & $9 \pm 1.41$ & $473.1 \pm 145.03$ & $60.3 \pm 28.64$ \\
\hline IGO & $176.4 \pm 50.77$ & $11.4 \pm 9.9$ & $803.5 \pm 937.27$ & $258.7 \pm 31.47$ & $0.45 \pm 0$ & $28.8 \pm I .4 \mid$ & $|3 \pm 1.4|$ & $7.5 \pm 0.71$ & $510.4 \pm 182.72$ & $53.6 \pm 13.01$ \\
\hline rGO & $193.4 \pm 44.67$ & $12.8 \pm 38$ & I, $548.6 \pm 785.45$ & $238.1 \pm 21.62$ & $0.38 \pm 0.09$ & $26.1 \pm 2.48$ & $|5.6 \pm 2.6|$ & $8.2 \pm 0.94$ & $793.4 \pm 195.43$ & $58.2 \pm 21.11$ \\
\hline$P$-value & 0.501 & 0.732 & $0.7 \mid 4$ & 0.389 & 0.436 & 0.681 & 0.603 & $0.24 I$ & 0.272 & 0.589 \\
\hline
\end{tabular}

Note: Results are presented as mean \pm standard deviation.

Abbreviations: Pl, placebo; DNPs, diamond nanoparticles; GNPs, graphite nanoparticles; NP, nanoparticle; pG, pristine graphene; sGO, small graphene oxide; IGO, large graphene oxide; rGO, reduced graphene oxide; BUN, blood urea nitrogen; TP, total protein; TGs, triglycerides. 


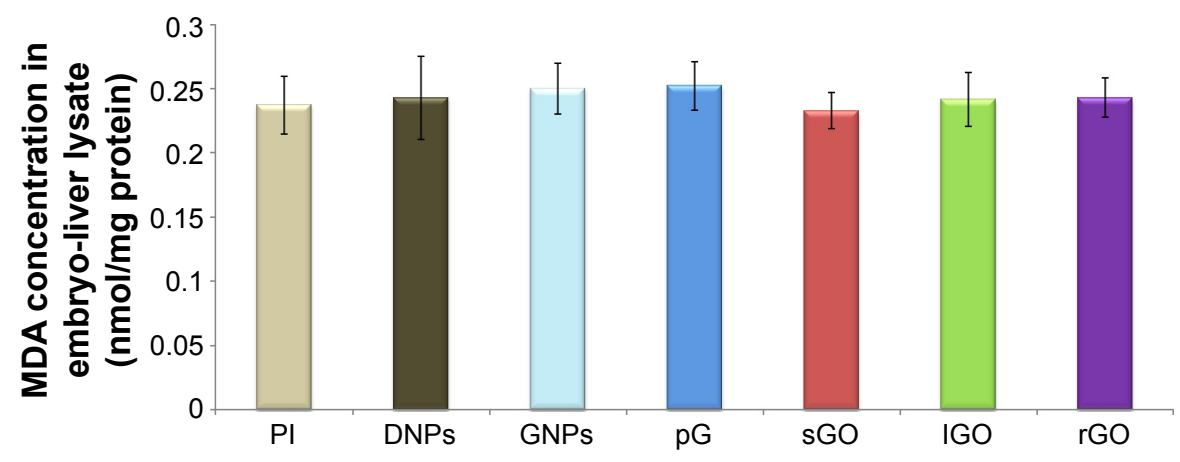

Figure 5 Concentration of malondialdehyde (MDA) in chicken-embryo liver lysate (nmol/mg protein).

Notes: Data are presented as averages of multiple determinations $(n=4)$, with error bars representing standard deviation. Differences were not significant $(P>0.05)$.

Abbreviations: PI, placebo; DNPs, diamond nanoparticles; GNPs, graphite nanoparticles; pG, pristine graphene; sGO, small graphene oxide; IGO, large graphene oxide; rGO, reduced graphene oxide.

investigate the impact of CNPs on RBC, which are very sensitive to any pathological changes. It ought to be emphasized that in the present study, CNPs were administered on the first day of embryogenesis, prior to the development of the blood-circulation system. Hematopoiesis in chicken embryos begins in the blood islands of the yolk sac during the second day of incubation, producing only nucleated erythrocytes and thrombocytes. ${ }^{41-43}$ As the blood islands grow, they merge to form a capillary network that drains into the vitelline veins, which bring nutrients and BCs to the newly formed heart of the embryo. ${ }^{42,43}$ The yolk sac remains hematopoietic for most of the embryonic development. ${ }^{41-43}$ Blood smears from the placebo, DNP, GNP, pG, and $1 \mathrm{GO}$ groups did not exhibit symptoms of inflammation or BC deformation (Figure 4). Erythrocytes appeared as flattened, elliptical cells with centrally positioned nuclei and agglomerated reticular material, as is normal for avian RBCs.

Of the CNPs included in this study, we have previously reported the biocompatibility of DNPs with RBCs..$^{18}$ Furthermore, an in vitro study ${ }^{44}$ demonstrated that adsorption of plasma components by 5 and $100 \mathrm{~nm} \mathrm{ND}$ (up to $500 \mu \mathrm{g} / \mathrm{mL}$ ) had no significant effect on blood plasma protein conformations or coagulation. It has been shown that $100 \mathrm{~nm}$ ND is localized around RBCs, while $5 \mathrm{~nm}$ particles penetrate $\mathrm{RBCs}$; both sizes of ND, however, neither was toxic at concentrations of 5 and $50 \mu \mathrm{g} / \mathrm{mL}$. Raman spectra did not show any changes in RBCs, hemoglobin, or hemoglobin-oxygenation state. ${ }^{45}$ On the other hand, Puzyr et al ${ }^{46,47}$ demonstrated that ND particles synthesized by the explosion method induced death in human white BCs and hemolysis of erythrocytes in vitro. The authors suggested that the damaging effects were due to 1) direct binding of ND to cell-membrane proteins, which may cause irreversible inhibition of their functions, and 2) an imbalance of electrolytic and osmotic equilibrium caused by adsorption of blood plasma protein components to ND particles. ${ }^{46}$ However, an in vivo model demonstrated that ND can attach to the RBC membrane and circulate with blood for at least 30 minutes, implying that ND has potential applications in medicine. ${ }^{25}$

In the present study, the shape and size of erythrocytes were preserved in the $1 \mathrm{GO}$ and sGO groups, with only a slight increase in the size of the RBC nucleus in sGO. In both groups, we did not observe any adhesion of GO flakes to the $\mathrm{RBC}$ surface during examination of peripheral blood smears. It has been shown that $\mathrm{GO}$ flakes can adhere to RBC surfaces; however, as in our study, there was no significant effect on erythrocyte morphology or membrane integrity. ${ }^{48}$ Furthermore, GO promoted the transition from a hemangioblast to a hemogenic endothelium. The promotion of both primitive and definitive hematopoiesis by GO is consistent with the fact that primitive and definitive progenitors are generated from hemogenic endothelium precursors. ${ }^{49}$

Our results indicate that $\mathrm{rGO}$ affects the shape and size of RBCs, which became more oval and generally smaller. However, we think that RBCs from the rGO group are immature forms of avian erythrocytes rather than indications of pathology, because they have irregular cytoplasmic polychromasia and a more rounded, pale nucleus. ${ }^{41}$ These features were also observed in the sGO group.

The biochemical indices of blood serum were not affected by any of the CNP treatments. Similar results have been reported previously. ${ }^{4,16-18,29,37}$ However, because blood serum homeostasis is tightly controlled, the lack of effects on serum indices might not necessarily reflect a lack of toxic effects. Therefore, we also examined the toxic effects of CNPs by screening for oxidative damage status in the livers of chicken embryos.

Lipid peroxidation was evaluated by measuring MDA levels. None of the investigated CNPs caused oxidative damage to the liver (Figure 5). In our previous report, ${ }^{37}$ 
we suggested that neither DNPs, 1GO, nor GNPs trigger oxidative stress in rats, and more importantly they may play a role in scavenging reactive oxygen species, since their levels were lower relative to the placebo group.

Surface charge has also been found to affect the biological properties of NPs. ${ }^{11}$ In the present study, $\zeta$-potential was measured for six different CNPs resuspended in WFI at the same concentration to compare and estimate the impact of solvent on the charge of CNPs, a property that determines their biodistribution and toxicity. Two of the investigated nanomaterials were positively charged, while the rest were negatively charged. pG had a low, positive $\zeta$-potential $(4.15 \mathrm{mV})$, which indicated pure colloidal stability and suggested that we may need to use a more polar solvent to get this hydrophobic material into solution. Compared to the literature, even Milli-Q water was a better solvent for dissolving $\mathrm{pG}$ at the same concentration while retaining its negative charge. ${ }^{16,17}$ A GNP solution was also positively charged $(35.57 \mathrm{mV})$, which is characteristic of GNPs despite the solvent, especially considering that in sterile saline solution at the same concentration, it was also positively charged $(12.5 \mathrm{mV}) .{ }^{29}$ Other CNPs were negatively charged, but we expected that interactions with egg albumin would alter the $\zeta$-potential to around $-9 \mathrm{mV}$, as has been previously demonstrated. ${ }^{16}$ For GNPs and rGO, stability improved in saline solution relative to Milli-Q water. ${ }^{18,29}$ However, for pG, sGO, and 1GO, stability decreased, and the $\zeta$-potential for DNPs was moderate. Nevertheless, it is worth investigating the charge of CNPs in biological media, such as egg albumin, to understand how charge can change after opsonin or another protein binds to the investigated nanomaterials.

According to Wang et al, ${ }^{50}$ the higher $\zeta$-potential of GO and GO derivatives causes more severe cell damage, but when the level of charge on its surface was high enough, charge did not directly correlate with toxicity. They also hypothesized that positively charged particles might disrupt the charge balance of the cell membrane and induce cell damage at a later stage, while negatively charged NPs have an inferior rate of endocytosis and do not utilize the clathrin-mediated endocytosis pathway. ${ }^{50}$ The results from our study did not identify such correlations among the CNPs investigated, either with regard to positive/negative charge or $\zeta$-potential. This indicates that the key toxicological factor may depend on another parameter, such as the identity of functional groups on the CNP structures. ${ }^{27}$

\section{Conclusion}

The data presented in this work demonstrated moderate toxicity of selected CNPs in the chicken-embryo model.
The investigated CNPs differed in size, flake shape, powder appearance, $\zeta$-potential, and presence of functional groups. CNPs affected the rate of survival of embryos, but survival was not correlated with $\zeta$-potential or positive/negative surface charge of the CNPs. Gross pathology indicated no abnormalities in any treatment group. An examination of RBCs revealed correctly shaped cells and nuclei, and only in the rGO group were erythrocytes identified as immature. We did not observe any negative impacts on body or organ weight, blood serum biochemistry, or oxidative damage to the liver. These results indicate that CNPs can circulate in the blood without causing any major side effects, and suggest that they may potentially be applied as vehicles for drug delivery or active compounds per se. However, further investigations of their properties, which depend on production methods and surface functionalization, are needed.

\section{Acknowledgment}

This report is a part of Natalia Kurantowicz's $\mathrm{PhD}$ thesis.

\section{Author contributions}

NK conceptualized, carried out the experiments with embryos, and drafted the manuscript. ES conceived the study and helped draft the manuscript. MG participated in the design of the experiment. AH participated in the statistical analysis. BS participated in the TEM analyses. GH participated in the RBC morphological analysis. RP participated in the determination of gross pathology and the evaluation of survival rates. WP participated in the FTIR analysis. AC participated in the design and coordination of experiments and helped draft the manuscript. All authors contributed toward data analysis, drafting and critically revising the paper, read and approved the final manuscript, and agree to be accountable for all aspects of the work.

\section{Disclosure}

The authors report no conflicts of interest in this work.

\section{References}

1. Panzarini E, Vergallo C, Mariano S, Dini L. A study on biocompatibility of carbon nanoparticles in HeLa cells dictated by synthesis and sterilization. Nanosci Nanometrol. 2016;2:1-7.

2. Geim AK, Novoselov KS. The rise of graphene. Nat Mater. 2007;6: 183-191.

3. Huang YX, Dong XC, Liu YX, Li LJ, Chen P. Graphene-based biosensors for detection of bacteria and their metabolic activities. J Mater Chem. 2011;21:12358-12362

4. Kurantowicz N, Sawosz E, Jaworski S, et al. Interaction of graphene family materials with Listeria monocytogenes and Salmonella enterica. Nanoscale Res Lett. 2015;10:23.

5. Jaworski S, Sawosz E, Kutwin M, et al. In vitro and in vivo effects of graphene oxide and reduced graphene oxide on glioblastoma. Int $J$ Nanomedicine. 2015;10:1585-1596. 
6. Krueger A. Diamond nanoparticles: jewels for chemistry and physics. Adv Mater. 2008;20:2445-2449.

7. Williams OA, Hees J, Dieker C, Jäger W, Kirste L, Nebel CE. Sizedependent reactivity of diamond nanoparticles. ACS Nano. 2010;4: 4824-4830.

8. Andersson OE, Prasad BL, Sato H, et al. Structure and electronic properties of graphite nanoparticles. Phys Rev B Condens Matter Mater Phys. 1998;58:16387-16395.

9. Ma J, Meng Q, Zaman I, et al. Development of polymer composites using modified, high-structural integrity graphene platelets. Compos Sci Technol. 2014;91:82-90.

10. Jastrzębska AM, Kurtycz P, Olszyna AR. Recent advances in graphene family materials toxicity investigations. J Nanopart Res. 2012; 14:1320

11. Celá $\mathrm{P}$, Veselá $\mathrm{B}$, Matalová E, Večeřa Z, Buchtová M. Embryonic toxicity of nanoparticles. Cells Tissues Organs. 2014;199:1-23.

12. Stern CD. The chick: a great model system becomes even greater. Dev Cell. 2005;8:9-17.

13. Vergara MN, Canto-Soler MV. Rediscovering the chick embryo as a model to study retinal development. Neural Dev. 2012;7:1-19.

14. Wolpert L. Much more from the chicken's egg than breakfast: a wonderful model system. Mech Dev. 2004;121:1015-1017.

15. Hamburger V, Hamilton HL. A series of normal stages in the development of the chick embryo. Dev Dyn. 1992;195:231-272.

16. Sawosz E, Jaworski S, Kutwin M, et al. Toxicity of pristine graphene in experiments in a chicken embryo model. Int J Nanomedicine. 2014;9: 3913-3922.

17. Szmidt M, Sawosz E, Urbańska K, et al. Toxicity of different forms of graphene in a chicken embryo model. Environ Sci Pollut Res Int. 2016; 23:19940-19948.

18. Strojny B, Grodzik M, Sawosz E, et al. Diamond nanoparticles modify curcumin activity: in vitro studies on cancer and normal cells and in ovo studies on chicken embryo model. PLoS One. 2016;11:e164637.

19. Roman D, Yasmeen A, Mireuta M, Stiharu I, Al Moustafa AE. Significant toxic role for single-walled carbon nanotubes during normal embryogenesis. Nanomedicine. 2013;9:945-950.

20. Chen LQ, Hu PP, Zhang L, Huang SZ, Luo LF, Huang CZ. Toxicity of graphene oxide and multi-walled carbon nanotubes against human cells and zebrafish. Sci China Chem. 2012;55:2209-2216.

21. Chang CC, Zhang BL, Li CY, et al. Exploring cytoplasmic dynamics in zebrafish yolk cells by single particle tracking of fluorescent nanodiamonds. Proc SPIE Int Soc Opt Eng. 2012;8272:827205-827208.

22. Li DY, Xue L, Zhu ZF, Zhao XY, Qian J. Graphene oxide nanoparticles for two-photon fluorescence imaging of zebrafish. Opt Quantum Electron. 2016;48:519.

23. Jeong JY, Cho HJ, Choi MJ, Lee WS, Chung BH, Lee JS. In vivo toxicity assessment of angiogenesis and the live distribution of nano-graphene oxide and its PEGylated derivatives using the developing zebrafish embryo. Carbon N Y. 2015;93:431-440.

24. Mu L, Gao Y, Hu X. L-cysteine: a biocompatible, breathable and beneficial coating for graphene oxide. Biomaterials. 2015;52:301-311.

25. Tsai LW, Lin YC, Perevedentseva E, Lugovtsov A, Priezzhev A, Cheng CL. Nanodiamonds for medical applications: interaction with blood in vitro and in vivo. Int J Mol Sci. 2016;17:1111.

26. Holt BD, Shawky JH, Dahl KN, Davidson LA, Islam MF. Distribution of single wall carbon nanotubes in the Xenopus laevis embryo after microinjection. $J$ Appl Toxicol. 2016;36:568-578.

27. Marcon L, Riquet F, Vicogne D, Szunerits S, Bodartb JF, Boukherroub R. Cellular and in vivo toxicity of functionalized nanodiamond in Xenopus embryos. J Mater Chem. 2010;20:8064-8069.

28. Lin YC, Wu KT, Lin ZR, et al. Nanodiamond for biolabelling and toxicity evaluation in the zebrafish embryo in vivo. J Biophotonics. 2016;9: $827-836$.

29. Kurantowicz N, Strojny B, Sawosz E, et al. Biodistribution of a high dose of diamond, graphite, and graphene oxide nanoparticles after multiple intraperitoneal injections in rats. Nanoscale Res Lett. 2015;10:398
30. Eigler S, Dotzer C, Hirsch A, Enzelberger M, Müller P. Formation and decomposition of $\mathrm{CO}_{2}$ intercalated graphene oxide. Chem Mater. 2012;24:1276-1282.

31. Wang GX, Shen XP, Wang B, Yao J, Park JS. Synthesis and characterisation of hydrophilic and organophilic graphene nanosheets. Carbon N Y. 2009;47:1359-1364.

32. Kuila T, Bose S, Khanra P, Kim NH, Rhee KY, Lee JH. Characterization and properties of in situ emulsion polymerized poly(methyl methacrylate)/graphene nanocomposites. Compos Part A Appl Sci Manuf. 2011;42:1856-1861.

33. Wang GX, Wang B, Park JS, Yang J, Shen XP, Yao J. Synthesis of enhanced hydrophilic and hydrophobic graphene oxide nanosheets by a solvothermal method. Carbon N Y. 2009;47:68-72.

34. Paredes JI, Villar-Rodil S, Martínez-Alonso A, Tascón JM. Graphene oxide dispersions in organic solvents. Langmuir. 2008;24:10560-10564.

35. Lian PC, Zhu XF, Liang SZ, Li Z, Yang WS, Wang HH. Large reversible capacity of high quality graphene sheets as an anode material for lithium-ion batteries. Electrochim Acta. 2010;55:3909-3914.

36. Mazurkiewicz M. Choroby Drobiu. Warsaw: Wydawnictwo Akademii Rolniczej; 2005.

37. Strojny B, Kurantowicz N, Sawosz E, et al. Long term influence of carbon nanoparticles on health and liver status in rats. PLoS One. 2015; 10:e144821.

38. Richardson CM, Hebert J. Device for on-site production of sterile water for injection in a disaster zone. 2013. Available from: http:// digitalrepository.trincoll.edu/cgi/viewcontent.cgi? article $=1316 \&$ context=theses. Accessed February 22, 2017.

39. Li Z, Wang C, Tian L, et al. An embryo of protocells: the capsule of graphene with selective ion channels. Sci Rep. 2015;5:10258.

40. Sawosz E, Jaworski S, Kutwin M, et al. Graphene functionalized with arginine decreases the development of glioblastoma multiforme tumor in a gene-dependent manner. Int J Mol Sci. 2015;16:25214-25233.

41. Claver JA, Quaglia AI. Comparative morphology, development, and function of blood cells in nonmammalian vertebrates. $J$ Exot Pet Med. 2009; 18:87-97.

42. Baumann R, Dragon S. Erythropoiesis and red cell function in vertebrate embryos. Eur J Clin Invest. 2005;35 Suppl 3:2-12.

43. Zon LI. Developmental biology of hematopoiesis. Blood. 1995;86: 2876-2891.

44. Mona J, Kuo CJ, Perevedentseva E, Priezzhev AV, Cheng CL. Adsorption of human blood plasma on nanodiamond and its influence on activated partial thromboplastin time. Diam Relat Mater. 2013;39: 73-77.

45. Lin YC, Tsai LW, Perevedentseva E, et al. The influence of nanodiamond on the oxygenation states and micro rheological properties of human red blood cells in vitro. J Biomed Opt. 2012;17:101512.

46. Puzyr AP, Tarskikh SV, Makarskaya GV, et al. Damaging effect of detonation diamonds on human white and red blood cells in vitro. Dokl Biochem Biophys. 2002;385:201-204.

47. Puzyr AP, Neshumayev DA, Tarskikh SV, Makarskaya GV, Dolmatov VY, Bondar VS. Destruction of human blood cells in interaction with detonation nanodiamonds in experiments in vitro. Diam Relat Mater. 2004;13:2020-2023.

48. Zhang X, Yin J, Peng C, et al. Distribution and biocompatibility studies of graphene oxide in mice after intravenous administration. Carbon $N Y$. 2011;49:986-995.

49. Garcia-Alegria E, Iluit M, Stefanska M, et al. Graphene oxide promotes embryonic stem cell differentiation to haematopoietic lineage. Sci Rep. 2016;6:25917

50. Wang A, Pu K, Dong B, et al. Role of surface charge and oxidative stress in cytotoxicity and genotoxicity of graphene oxide towards human lung fibroblast cells. J Appl Toxicol. 2013;33:1156-1164. 


\section{Publish your work in this journal}

The International Journal of Nanomedicine is an international, peerreviewed journal focusing on the application of nanotechnology in diagnostics, therapeutics, and drug delivery systems throughout the biomedical field. This journal is indexed on PubMed Central,

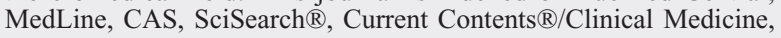

Journal Citation Reports/Science Edition, EMBase, Scopus and the Elsevier Bibliographic databases. The manuscript management system is completely online and includes a very quick and fair peer-review system, which is all easy to use. Visit http://www.dovepress.com/ testimonials.php to read real quotes from published authors.

Submit your manuscript here: http://www.dovepress.com/international-journal-of-nanomedicine-journal 